\title{
VIVÊNCIAS DE MULHERES BRASILEIRAS COM INCONTINÊNCIA URINÁRIA ${ }^{1}$
}

\author{
Rosângela Higa², Carlos Roberto Soares Freire de Rivorêdo ${ }^{3}$, Lia Keuchguerian Campos ${ }^{4}$, Maria Helena de \\ Moraes Lopes ${ }^{5}$, Egberto Ribeiro Turato ${ }^{6}$
}

${ }^{1}$ Artigo extraído da tese intitulado - Significados psicossociais da perda urinária para mulheres de condições socioeconômicas menos favorecidas: um estudo clínico-qualitativo, apresentado ao Programa de Pós-graduação do Departamento de Tocoginecologia da Faculdade de Ciências Médicas (FCM) da Universidade Estadual de Campinas (UNICAMP), 2010. Pesquisa financiada pela Fundação de Amparo à Pesquisa do Estado de São Paulo.

${ }^{2}$ Doutora em Tocoginecologia. Enfermeira do Hospital da Mulher Prof. Dr. José Aristodemo Pinotti -UNICAMP. São Paulo, Brasil. E-mail: rosangelahiga@bol.com.br

${ }^{3}$ Doutor em Ciências Médicas. Professor Assistente Doutor do Departamento de Pediatria da FCM/UNICAMP. São Paulo, Brasil. E-mail: carrivo@uol.com.br

${ }^{4}$ Mestranda em Ciências Médicas pelo Departamento de Psicologia Médica e Psiquiatria da FCM/UNICAMP. São Paulo, Brasil. E-mail: liacampos81@uol.com.br

${ }^{5}$ Doutora em Ciências Biológicas. Professora Associada do Departamento de Enfermagem da FCM/UNICAMP. São Paulo, Brasil. E-mail: mhbaenaml@yahoo.com.br

${ }^{6}$ Doutor em Saúde Mental. Professor Associado do Departamento de Psicologia Médica e Psiquiatria da FCM/UNICAMP. São Paulo, Brasil. E-mail: erturato@uol.com.br

RESUMO: Nosso objetivo foi aprofundar os conhecimentos sobre as vivências com a perda urinária entre mulheres brasileiras. Utilizou-se o método clínico-qualitativo com entrevistas semi-dirigidas. Oito mulheres, faxineiras, de 30 a 45 anos, de baixa situação socioeconômica, com queixa de perda urinária e que nunca realizaram tratamento, foram selecionadas pela técnica "bola de neve", com fechamento amostral pelo critério de saturação. A técnica de análise de conteúdo com abordagens psicodinâmicas possibilitou a criação de duas categorias: um assunto velado e uma vivência solitária. Para as mulheres, a perda urinária é um assunto que deve ser escondido, um obstáculo nas interações interpessoais, um estigma que impede a busca de tratamento. Elas convivem com o medo e a vergonha. Calam-se, sofrem sozinhas, e para resistir, reagem com a solidão. Concluímos que as mulheres incontinentes preferem o silêncio a ter que pedir ajuda, encontram no isolamento a forma de proteção, e na solidão, a sobrevivência.

DESCRITORES: Incontinência urinária. Pesquisa qualitativa. Saúde da mulher. Acontecimentos que mudam a vida. Impacto psicossocial.

\section{LIFE EXPERIENCES OF BRAZILIAN WOMEN WITH URINARY INCONTINENCE}

\begin{abstract}
Our aim was to amplify the knowledge about the life experiences with urinary incontinence of Brazilian women. Were used the clinical-qualitative method with semi-directed interview. Eight women, housemaids, the 30 to 45 years, low socioeconomic status, with complain of urinary incontinence and never seek treatment, were selected by the "snowball" technique, and the size closing was by saturation criterion. The content analysis technique and psychodynamic approaches allowed the creation of two categories: one hidden problem and lonely life experience. For women, urinary incontinence is a problem that should be hidden, one obstacle in interpersonal interactions, a stigma that prevents the search for treatment. They live in fear and shame. They silenced, suffer alone, and to resist, react with the loneliness. The conclusions were that incontinent women prefer silence to having to ask for help, the insulation in was the protection form and aloneness, survival.
\end{abstract}

DESCRIPTORS: Urinary incontinence. Qualitative research. Women's health. Life change events. Psychosocial impact.

\section{VIVENCIAS DE LAS MUJERES BRASILEÑAS CON INCONTINENCIA URINARIA}

RESUMEN: Nuestro objetivo fue profundizar los conocimientos acerca de las experiencias con la pierda de orina de mujeres brasileñas. Utilizamos el método clínico-cualitativo y entrevistas semi-dirigidas. Ocho mujeres incontinentes, empleadas domésticas, con edad entre 30 a 45, bajo estatus socioeconómico y que nunca trataran la incontinencia urinaria, fueran seleccionadas por la técnica de "bola de nieve" y pelo criterio de saturación. La técnica de análisis de contenido con enfoque psicodinámico permitió la creación de dos categorías: una cuestión encubierta y una experiencia solitaria. Para las mujeres, la incontinencia urinaria es un problema que debe ser ocultado, un obstáculo en las interacciones interpersonales y un estigma que impide la búsqueda de tratamiento. Viven en el miedo y vergüenza. Silencian, sufren solas y reaccionan con la soledad. Concluimos que estas mujeres prefieren el silencio a tener que pedir ayuda, encuentran en el aislamiento, la forma de protección, y en la soledad, la supervivencia.

DESCRIPTORES: Incontinencia urinaria. Investigación cualitativa. Salud de la mujer. Acontecimientos que cambian la vida. Impacto psicosocial. 


\section{INTRODUÇÃO}

As repercussões psicológicas da Incontinência Urinária (IU) em mulheres causam aflição e incapacidades, as quais têm levado a significativa morbidade devido a sentimentos de vergonha e medo de sofrer rejeição. ${ }^{1-3}$ Esse fenômeno é percebido como não aceitável para a vida social, com perda das propriedades saudáveis do corpo. As mulheres sentem-se socialmente desprezadas e culpadas pelo abandono da sociedade. ${ }^{4}$

A perda inesperada de urina é relatada pelas mulheres como ameaça para a sua autoestima. Esta ameaça fornece fortes incentivos para o desenvolvimento de sistemas eficazes de cuidado a fim de se manterem continentes, ou empregam mecanismos de defesa, como a negação, para proteger sua autoestima. ${ }^{5}$

A IU é uma condição constrangedora com profundas sequelas psicossociais e há evidências de implicações psicológicas na vivência familiar, profissional e social. O medo do odor demonstra ser de alto impacto na restrição social. ${ }^{6}$ Além disso, sentem vergonha quando esta "desgraça" sucede em público, principalmente em eventos sociais. Percebem também medo em perder o emprego ou mudar de função por restrições laborais causadas por limitações das atividades..$^{2-3}$

Contudo, o grau e a amplitude da angústia experimentada estão relacionados com as reações de cada pessoa e como cada indivíduo percebe a sua incontinência. Os significados dados aos problemas de saúde são estruturantes de nossas vidas. ${ }^{7}$

As mulheres também vivenciam a perda urinária como tabu, tentam manipulá-la para controlar suas funções corporais e demonstrar continência para viver com certa "normalidade". O controle das eliminações em torno da IU é construído socialmente, visto que existem normas culturais quanto ao manejo das eliminações por serem associadas à sujeira e quando alguns adultos não conseguem cumpri-los, são estigmatizados. ${ }^{9}$

Os estudos indicam que a atitude do indivíduo sobre a sua real capacidade de convivência com a IU deriva de idéias culturais sobre o que a incontinência simboliza para cada um, para cada sociedade ${ }^{10}$ assim as atitudes de aceitabilidade da perda do controle sobre as funções corporais, decorrente da IU, se alteram em relação aos valores culturais e crenças sobre o não controle da limpeza e uso de fraldas. ${ }^{11}$

Observando pesquisas com mulheres de diferentes culturas, os significados da perda urinária para mulheres orientais e ocidentais não mostraram diferenças, elas relatam sentimentos de desespero, impotência, desamparo e angústia. Todavia, na cultura religiosa, a incontinência pode limitar a vida religiosa de judias e muçulmanas devido à necessidade de limpeza para a prática da oração. ${ }^{7}$

Para as mulheres brasileiras a IU representa também impacto sobre a vida social e o bem-estar. O manejo da IU faz com que a mulher vivencie constantes sentimentos, muitas vezes negativos, que podem levá-las a tristeza e depressão. ${ }^{9} \mathrm{Ou}$ tros estudos apontam que entre $41 \%$ e $79 \%$ das brasileiras não procuram por ajuda médica para tratar da IU. Um dos principais motivos alegados é porque consideram o problema urinário irrelevante e demonstram desvalorização desse sintoma. ${ }^{12-14}$ Atitudes como estas impedem a realização do diagnóstico e tratamento precoce, agrava os sintomas, prejudica os desempenhos sexual, ocupacional e social, e interfere negativamente na qualidade de vida. ${ }^{3}$ Porém, a literatura brasileira mostra poucos estudos qualitativos com abordagem sobre a vivência de mulheres com perda urinária e raramente aprecia os aspectos subjetivos dos significados desse sintoma.

Neste contexto, considerando o grande número de mulheres brasileiras pertencentes a grupos sociais de trabalhadoras com baixa situação socioeconômica e educacional, ${ }^{15}$ pressupomos que para esse grupo de mulheres em idade reprodutiva, o quadro de deficiência social e educacional interfere nos significados da IU e na adaptação dos mecanismos desenvolvidos para lidar com a perda de urina na sua rotina diária. Analisando que a perda urinária aos esforços é o tipo de IU mais prevalente entre as mulheres, as atividades laborais com maior demanda de esforços físicos podem agravar os sintomas da IU, porém as dificuldades econômicas com a possível perda da remuneração do dia não trabalhado para uma consulta médica, e a desinformação sobre este problema urinário são fatores que interferem na procura por tratamento.

Diante disso, questionamos: as experiências vivenciadas com a IU, por este grupo de mulheres, distinguem de outras populações femininas estudadas? Entendemos que as pesquisas são ferramentas para que os sentimentos das mulheres com IU em diferentes contextos socioculturais sejam contemplados pelos profissionais de saúde. Principalmente os estudos qualitativos ancorados em referenciais psicodinâmicos, que visam investigar a compreensão dos processos dinâmicos, das 
hipóteses de que aquilo que as pessoas dizem e fazem possui um significado, que existem padrões para o comportamento das pessoas os quais podem ser discernidos e observados a partir da narrativa de vida do indivíduo, e estão agregados a todos os afetos que o permeiam a compreensão simbólica sobre a natureza e a extensão do conflito subjacente. ${ }^{16}$

Compreender as vivências e o impacto psicossocial da perda urinária são aspectos fundamentais para que os profissionais da saúde aprimorem o enfoque psicológico na avaliação, diagnóstico e conduta desse problema urinário. As intervenções provenientes do conhecer e do trocar experiências podem resultar em maiores benefícios para as mulheres, contribuindo para que a vivência com a IU torne-se um momento de vida menos sofrido. Sendo assim, o presente estudo teve como proposta aprofundar os conhecimentos sobre as vivências com a perda urinária na realidade da mulher brasileira, em um grupo sócio-econômico específico.

\section{MÉTODO}

Para este estudo foi utilizado o Método Clínico-Qualitativo. Trata-se especificamente de um método adaptado e aperfeiçoado a partir da metodologia qualitativa para a realidade psicológica e clínica que abrange duas áreas de extrema complexidade: dos conhecimentos clínico-psicológicos das relações interpessoais e das concepções epistemológicas do método qualitativo da pesquisa desenvolvida a partir das ciências humanas. Além disso, busca interpretar cientificamente os significados das experiências de vida, sobreposto a um quadro especifico da saúde que permite compreender a vivência do processo das angústias, do sofrimento dos indivíduos mediante a um determinado problema na relação saúde-doença. ${ }^{17}$

O método clínico permite que sentimentos e necessidades humanas sejam mostrados e compreendidos, privilegia a escuta da fala do sujeito com suas riquezas de expressões e entonações emocionais, e admite a observação do comportamento por meio de sua linguagem não-verbal. Assim sendo, a dinâmica da entrevista clínicopsicológica, na pesquisa clínico-qualitativa, caracteriza-se como um precioso instrumento de conhecimento interpessoal. A sua utilização em profundidade, com observação ampla e livre, permite a obtenção de dados de natureza objetiva e subjetiva, como opiniões, valores e atitudes dos sujeitos pesquisados. ${ }^{17}$
O estudo foi desenvolvido em uma cidade do interior do estado de São Paulo. Por se tratar de pesquisa para interpretar os significados que as pessoas atribuem aos fenômenos da IU, optouse por uma amostra intencional de mulheres, com IU e não realizavam tratamento, escolhidas deliberadamente em função da sua importância em relação ao tema e da representação social para este estudo. Diante disso, a captação dos sujeitos ocorreu segundo a técnica da bola-de-neve. ${ }^{18}$

A primeira participante do estudo foi identificada por meio de busca ativa, ou seja, a pesquisadora identificou, na região acerca de sua residência e local de trabalho, mulheres que tinham atividade laboral remunerada, como faxineiras ou diaristas. Após explicar os objetivos do estudo e confirmar os critérios de inclusão dos sujeitos (ter atividade laboral com esforço físico, ter queixa de perda urinária e nunca ter realizado tratamento, idade entre 20 e 45 anos, escolaridade até o ensino fundamental completo e baixa renda familiar), convidou-a a participar do estudo e realizou a primeira entrevista.

A seguir, esta primeira entrevistada indicou a segunda participante e assim sucessivamente. Em contato prévio, por telefone, foram convidadas aquelas que confirmaram os critérios de inclusão. Quando novos dados não mais contribuíram significativamente para revisão dos objetivos iniciais do estudo, o critério de saturação norteou o fechamento da amostra. ${ }^{19}$ Para identificar a saturação dos dados, a análise foi realizada progressiva e simultaneamente à sua coleta.

O recorte do objeto delimitou-se a oito mulheres em idade reprodutiva (entre 30 e 45 anos) que tinham história de qualquer perda involuntária de urina e nunca fizeram tratamento. Todas atuavam em serviços de limpeza (faxineiras), tinham entre dois e quatro filhos, uma era solteira e as demais mantinham união estável, e pertenciam a classe socioeconômica e educacional desfavorecida, ou seja, em média estudaram por cinco anos (entre zero a oito anos), viviam em famílias de quatro até 11 membros com renda familiar máxima de 4,5 salários mínimos. Salientamos que, por tratar-se de pesquisa qualitativa, a priori, as características individuais dos sujeitos não foram avaliadas na análise das falas e discussão dos resultados.

As entrevistas foram realizadas na instituição onde atua a pesquisadora, com intuito de garantir um local privativo e tranqüilo. Para que o deslocamento não acarretasse ônus financeiro, as mulheres receberam auxílio transporte e alimentação, financiado por agência de fomento à pesquisa. 
A entrevista foi semi-dirigida de questões abertas $^{20}$ realizada individualmente, gravadas e literalmente transcritas. Por meio de um roteiro que iniciava com uma pergunta: "Fale-me como está sendo a sua experiência com a perda urinária" foram exploradas as vivências psicossociais mediante a perda de urina.

Essa técnica de entrevista consiste na utilização de um roteiro/diário de campo, como instrumento auxiliar de pesquisa, elaborado especificamente para contemplar os itens sobre os objetivos propostos e para orientar uma "conversa com finalidade" facilitando a abertura, ampliação e aprofundamento da comunicação. ${ }^{21}$

A técnica de análise temática de conteúdo ${ }^{21-22}$ com leituras flutuantes do corpus das entrevistas possibilitaram a criação de duas categorias: um assunto velado; uma vivência solitária, validadas por pesquisadores membros do Laboratório de Pesquisa Clínico-Qualitativa da Universidade na qual a pesquisa se desenvolveu. A análise dos dados foi fundamentada nas abordagens psicossociais e psicodinâmicas.

Para a viabilização, o estudo cumpriu as normas preconizadas para pesquisas com seres humanos. A anuência dos sujeitos se deu por meio da assinatura do Termo de Consentimento Livre e Esclarecido, após a obtenção de parecer favorável do Comitê de Ética em Pesquisa da Universidade (Processo n ${ }^{\circ} 820 / 2007$ ).

\section{RESULTADO}

\section{Um assunto velado}

Embora estas mulheres tenham aceitado a participar da pesquisa, no discurso inicial da entrevista, em frases curtas, uma das mulheres nega os sintomas da perda urinária, enquanto a outra recusa a pensar sobre sua IU.

Eu não tenho a urina solta [...] é só quando eu vou rir $[\ldots]$ (S8).

\section{Eu prefiro não pensar sobre isso [...] (S1).}

Percebemos que ao mesmo tempo em que negam, elas confirmam os episódios de IU, preferindo não pensar neste problema. Estes comportamentos já demonstravam que este era um problema de saúde que deveria ser escondido.

Embora elas estivessem tentando esconder, minimizar a situação ou subestimar o problema, ao serem questionadas sobre suas vivências com a IU relatam que perder urina é um problema comum na vida da mulher, então tudo é normal.
Eu vou ter. Minha mãe teve [...] então eu posso ter também [...]. Eu sou normal, eu acho que não tenho problemas [...] [choro] (S3).

Nessas falas, elas demonstram a tentativa de evitar entrar em contato com a angústia de ter uma doença que incomoda e traz constrangimento. Neste caso a negação pode ser uma forma que essas mulheres desenvolveram para lidar com seu problema urinário, ao poucos perceberam um significado diferente para a IU, como algo anormal, como um problema real.

De acordo com os relatos, para as mulheres, é extremamente embaraçoso falar sobre a perda urinária, de tal modo que foi possível notar que elas não comentam porque pressupõem que as outras pessoas também preferem não tocar nesse assunto.

Pode ver que as pessoas não ficam comentando aquilo [...]. Então eu fico na minha, fico quietinha, nem falo. [...] [risos] [...]. Nunca ninguém comentou, não sei se ficam constrangidas também. A gente sempre fica com vergonha de falar (S2).

Neste discurso, é possível perceber que, para a mulher incontinente, o constrangimento e a vergonha são obstáculos para que as pessoas falem sobre esse assunto.

Eu sempre penso o que as pessoas iam pensar. Sempre me preocupava o que as pessoas iam pensar. [...] [risos] [...]. Algumas maldades! Alguma coisa ruim $[\ldots]$ (S4).

A fala acima mostra a crença de que os outros também não comentam sobre a IU porque pensamentos desagradáveis podem emergir. A reação esteriotipada evidencia a dimensão dos sentimentos de apreensão vivenciados.

A concepção de que a perda urinária é um tema que deve ser evitado, algo que deve ser escondido, tentam justificar o seu silêncio por meio da imaginação que elas têm dos pensamentos das pessoas. Elas se inquietam em imaginar o que os outros podem pensar sobre a perda urinária e em geral avaliam como algo ruim. Daí o medo...

Sempre tem uma amiga que vai chegar e vai falar. Mas você fica com receio de chegar e tocar nesse assunto, o que ela vai falar para você, saber o que ela pensa! (S5).

O medo de ser julgada e mal interpretada leva essas mulheres a evitar comentários, omitir opiniões, enfim, a silenciar. $O$ temor em receber uma crítica a respeito da sua IU é tão grande que se cala mesmo diante da melhor amiga. Ao deixarem claro que a IU é uma condição de saúde que deve ser ocultada, a todo o momento buscam maneiras, dispositivos ou 
estratégias comportamentais para escondê-la, como tentativa para demonstrar continência.

Eu fiz xixi naquela hora e daqui a pouco eu vou lá e já troco. Agora, assim, com a roupa, dependendo o lugar que eu estou aí não vai ter jeito! (S2).

Embora os relatos apontem certa adaptação às estratégias, como o uso de forro, absorventes ou a troca de roupa íntima para conter a perda de urina durante a sua rotina diária, parece que as manobras nem sempre podem dar certo e não lhes garante segurança alguma frente a este mal.

Os sentimentos vivenciados, como a vergonha, o medo e a ansiedade, parecem gerar impedimentos para que solicitem auxílio para lidar com esse problema, de tal modo que não falam sobre esse assunto tão temido.

Mas quando vou ao médico eu não comento mesmo, nunca falei nada [...]. Eu acho que eu não sei [...]. A gente fica com vergonha, é [...]. Eu acho que sim (S2).

Estas mulheres verbalizam que procuram por tratamento, porém, falar para o médico sobre a sua IU significa assumir sua condição de incontinente, ou seja, ter de expor seus sentimentos mais íntimos. Neste momento, os sentimentos vivenciados parecem ser tão intensos que impõem limites a ponto de bloquear sua fala, com demonstração de que ocultar sua disfunção urinária evitará possíveis conflitos internos.

[...] eu ia falar e falava de qualquer outra coisa, da infecção, do que eu estava sentindo [...]. Mas entrar nesse assunto, eu não entrava em detalhes não. Ah! Eu não sei, eu não sei o que ela iria falar para mim sobre isso [...] (S5).

Nas falas acima, nas quais as mulheres manifestam tentativas de expor o seu problema, ratificam que além da vergonha, falar sobre a perda urinária significa algo penoso. De forma que buscam no profissional da saúde possíveis atitudes e preconceitos para justificar seu silêncio e evidencia, mais uma vez, que elas preferem ocultar, possivelmente negar a sua condição, assim como seus agravantes, a ter de buscar ajuda eficaz para o tratamento da IU.

\section{Uma vivência solitária}

As falas das mulheres determinam uma marca que as diferencia das outras pessoas, sentem vergonha, temem que o problema seja percebido e procuram escondê-la de todas as formas, evidenciando que vivenciam a perda urinária como um estigma.
Com sentimentos de portadora de um estigma, a perda urinária é uma ameaça para a convivência social e que, portanto, deve ser evitada. Nessa vivência relatam sentimentos de aflição e ansiedade.

Incomoda esse negócio de você ficar preocupada em estar num lugar e acontecer isso, sabe! Então até eu sinto meio estranho, assim, sensação estranha porque está vazando tudo (S5).

Os sinais que a urina pode deixar e as experiências com transtornos emocionais parecem interferir nas relações interpessoais. As mulheres estudadas demonstram vivenciar a perda urinária como uma situação socialmente inaceitavel.

Às vezes a gente fica com vergonha de sentar, levantar e ver que está molhada. Ah! Eu me sinto mal, me sinto muito mal [...]. Me sinto envergonhada! Porque ficar perdendo assim, fazendo xixi na roupa não é bom não! (S3).

Como mulheres, os incômodos, a vergonha, as maneiras constrangedoras relatadas revelam que perder urina é algo indecente, impuro e que pode ferir o pudor das pessoas, portanto deve ser escondido. Algumas vezes, na tentativa de não revelar o seu problema, a roupa molhada e o odor de urina exalado denunciam a sua condição.

A gente vê o povo falando, aquela mulher está fedendo urina. Aí a gente pensa [...]. Estão falando da gente também! Quando isso acontece, procuro mais me distanciar, não ficar muito perto, porque xixi [...] (S2).

Como meio de preservação dos possíveis sentimentos que podem ocorrer diante dos incidentes em público elas se retraem. Ao se afastarem das pessoas evidencia que elas buscam no isolamento uma tentativa de solução para esses problemas.

Nos dias de hoje, as normas de sobrevivência pregam que todas as pessoas necessitam manter a convivência social, assim, percebemos que as mulheres estudadas tentam manter estes vínculos sociais, porém, quando este contato acontece, a perda urinária impõe restrições e limitam a convivência.

[...] eu, simplesmente se estiver em péeu disfarço, saio de fininho e vou embora (S2).

Quando eu perco urina eu volto rapidinho para casa [...]. Não gosto de ir à festa longe, eu [...] (S3).

Nos relatos acima, percebemos que a mulher que sofre de IU se priva dos vínculos afetivos e sociais. Embora ela tenha um convívio social, este é marcado pela distância, prevalece então, a solidão. 
Como trabalhadoras, nos momentos em que precisam aproximar-se das pessoas durante a atividade laboral, o medo de vivenciarem a vergonha em público é intenso e estas mulheres criam medidas preventivas para evitar que a perda urinária aconteça na frente dos outros e seja por eles percebida.

[...] no trabalho a gente já se previne, coloca um forrinho fininho e fica ali. Tenho um medo disso! [...] Já pensou ficar cheirando a xixi e andando pelo meio do povo! (S1).

Pela própria natureza é difícil conter e controlar o odor de urina, uma vez que pode escapar e transpor as barreiras de proteção. A vergonha e o medo da visibilidade do seu problema trazem experiências de angústia e inquietação quando percebem o cheiro de urina.

Quando eu sinto que isso vai descer eu corro para o banheiro para não acontecer onde eu trabalho porque tem muita gente então você fica com muita vergonha [...] fica com aquilo incomodando, que todo mundo está vendo $[\ldots]$ (S5).

Elas tentam esconder seu problema urinário, se afastar, a fim de evitar que os outros também notem. Ser uma trabalhadora com IU demonstra ser exaustivo, sofrido e desumano. Estas mulheres batalham o tempo todo para conseguirem conviver cercadas de pessoas, no entanto, sua vivência acaba sempre por se tornar solitária.

\section{DISCUSSÃO}

Conforme é salientado nas falas das mulheres, os significados das implicações na vivência com a IU vão muito além da perda de controle ou do inconveniente físico que afeta o bem-estar emocional, psicológico e social. A perda urinária significa algo proibido, com sentimento de exposição semelhantes à obscenidade, as quais reduzem a interação com as pessoas. Somando-se a isso, demonstram apreensão com a sua imagem, se preocupam excessivamente com a opinião do outro e temem serem criticadas e preteridas.

Essas mulheres preferem não falar sobre seu problema urinário por experimentarem uma vulnerabilidade emocional com diversos sentimentos, como o medo, vergonha, constrangimento e humilhação na presença das pessoas. Assim sendo, elas falam consigo mesmas e constantemente seus pensamentos estimam o que as pessoas pensam sobre a IU, como sendo algo feio, ruim e maléfico. Contudo, esses esforços demonstram uma tentativa de proteção, uma vez que parecem projetar no outro a sua própria rejeição, os seus preconceitos com a perda urinária.

Percebemos em nosso estudo que o desejo de manter a perda urinária como um assunto velado traz a questão da visibilidade da IU como um estigma social. Um atributo que produz um amplo descrédito na vida do sujeito; em situações extremas nomeadas como "defeito", "falha" ou desvantagem em relação ao outro; que reduz as oportunidades, esforços e movimentos, não atribui valor, impõe a perda da identidade social e determina uma imagem deteriorada. ${ }^{23}$

Observamos nas frases curtas e incompletas, nas falas estereotipadas e nos choros, que elas percebem os limites físicos, emocionais e sociais impostos pela perda urinária, e evidenciam a vivência da IU com sentimentos de estigmatizada. Reagem tentando escondê-la, demonstrar continência para se proteger, porém a visibilidade da perda urinária por meio de um sinal na roupa e pelo odor de urina exalado explicitam a sua condição de incontinente.

As experiências de mulheres incontinentes estudadas por outros autores revelam que o estigma foi associado ao medo da reação das outras pessoas, incluindo dos profissionais de saúde, e ao defeito de um corpo incapacitado de controlar suas funções corporais. ${ }^{24}$ As mulheres por nós estudadas tentam se habituar à nova forma de viver ao demonstrarem que não conseguem buscar ajuda e, quando procuram pelo médico, experimentam um turbilhão de sentimentos que bloqueiam a sua fala. Não conseguiram nem mesmo contar seu problema urinário ao seu médico, mobilizadas por uma intensa vergonha e não aceitação.

Na sociedade, o odor se torna um símbolo pessoal, os cheiros são convertidos em sensações físicas para avaliações simbólicas e traz consigo uma rotulagem. Assim sendo, os sinais da IU tornam-se uma condição de estigma, uma ameaça, pois é um sintoma que é associado com sujeira. ${ }^{25}$ Diante disso, em outros estudos as mulheres demonstram preocupações expressas com a limpeza e a higiene pessoal. ${ }^{24}$ Trocam inúmeras vezes de roupas, ficam sempre próximas ao banheiro, não se sentam e chegam, até mesmo, ao ponto de se excluir do convívio social.

O relato da vergonha e da sensação de medo diante de seu problema urinário parece que as levam a introjetar esse estigma, se retrair e buscar o isolamento como uma forma de proteção. De tal modo que essas mulheres percebem o preconceito projetado na dinâmica social, na maioria das vezes 
ninguém precisa dizer nada, elas sentem e reagem se impondo a solidão. Entretanto, o isolamento pareceu não ser a melhor alternativa, as reações estereotipadas indicaram um sentimento de solidão forçada, não foi escolhida, foi aplicada como uma penalidade ao seu estigma.

Como mulheres trabalhadoras, e por vezes provedoras do lar, precisam ser aceitas em seu grupo de trabalho. Similarmente aos relatos de outro estudo ${ }^{26}$ elas tentam manter uma identidade social como continente e, se seu problema é exposto, a identidade social muda, passa de uma "normal" para outra "anormal", inaceitável socialmente. Assim sendo, buscam diversas maneiras para sustentar a normalidade adaptando dispositivos e estratégias comportamentais para conter a perda de urina.

A identificação das estratégias adotadas, como usar forro/fralda, ficar com a roupa molhada e cheirando a urina, e correr ao banheiro, pode ser uma barreira psicológica para o convívio social. Haja vista que são atitudes e comportamentos próprios da infância. A falta de controle dos esfíncteres é um fenômeno socialmente reservado às crianças e no adulto é percebido como um "defeito", portanto não é permitido. Contudo, essas mulheres não reclamam, sofrem sozinhas, buscando a solidão para se proteger, como uma solução de sobrevivência.

Percebemos que estas mulheres sofrem custos emocionais decorrentes dessa condição com profundas consequências sociais. Expor a perda urinária é tão difícil que parece significar algo proibitivo, em decorrência disto, o isolamento parece que se torna mais fácil. A literatura reforça que as mulheres reagem com diferentes graus de transtorno emocional frente a esse problema urinário, que podem destruir a confiança e o respeito que o individuo tem por si e impedir a procura por ajuda.?

Sabe-se que para os membros das classes menos favorecidas socioeconomicamente, a origem de algumas doenças, recobertas pelas especificidades aparente da hereditariedade, significa dizer que ela é inevitável e fatal, assim, nada pode ser feito para evitá-la. Essas pessoas enfrentam também dificuldades sociais e culturais ao tentarem exprimir e descrever ao médico os sintomas de sua doença, as quais, muitas vezes as levam a relevar o problema, outras esperam que a doença alcance intensidade que impeça o uso normal do seu corpo. ${ }^{27}$
Nesse contexto, embora as mulheres estudadas não tenham expressado oralmente, não afastam a possibilidade de que dificuldades na expressão verbal, decorrentes da baixa situação sócio-econômica-educacional, podem influenciar na forma que as mulheres vivenciam a sua perda urinária e sejam barreiras para que elas busquem por tratamento médico.

\section{CONCLUSÃO}

Para as mulheres brasileiras, jovens, trabalhadoras e de baixa situação socioeconômica, a vivência com a perda urinária mostrou ser semelhante aos estudos realizados com mulheres de diferentes culturas, como algo proibitivo, que fere a sensibilidade das pessoas e leva a experiência de um estigma. Elas acreditam que a IU é um assunto que deve ser escondido e percebem como obstáculo nas interações interpessoais; convivem com o medo, a vergonha e sofrem caladas, a ponto de preferir o silêncio a ter de pedir ajuda.

As mulheres por nós estudadas utilizam de manejos comportamentais e mecanismos psicológicos para se defender dos sentimentos vivenciados, buscam nas estratégias adotadas mostrar uma identidade como continente, o que é muito difícil considerando que as marcas deixadas e o odor exalado de urina podem denunciar a sua condição.

$\mathrm{O}$ estudo revela que as mulheres temem reações restritivas tanto da sociedade como do profissional da saúde. Os significados da perda urinária e os sentimentos vivenciados aumentaram as dificuldades em expressar seu problema para estes profissionais. Porém, não houve manifestação de possíveis implicações decorrentes da baixa condição socioeconômica e educacional nas adaptações dos mecanismos desenvolvidos para lidar com esse problema urinário, na forma com que as mulheres incontinentes agem e reagem diante da sua condição ou na procura por tratamento.

O estudo atual mostra que o significado da IU perpassa os problemas econômicos e educacionais da nossa população e evidencia as inquietações psicológicas e sociais vivenciadas por este grupo de mulheres ao legitimar que a IU é um problema que deve ser escondido como uma forma de proteção aos sentimentos de angústia, medo e vergonha, e pode levar a uma vida solitária como alternativa de sobrevivência diante das marcas profundas de um estigma que interfere na sua qualidade de vida. 


\section{Relevância para a prática}

A prioridade e relevância deste estudo estão nas contribuições aos profissionais que atuam na saúde da mulher auxiliando para que aprimorem o acolhimento por meio da valorização da "escuta". O enfoque psicológico, por meio dos diagnósticos de enfermagem de domínio psicossocial, pode ser utilizado como subsídio para o diagnóstico da IU e inserção de intervenções psicológicas e sociais com vistas a buscar resultado eficaz e resolutivo para melhorar a qualidade de vida dessa população.

O estudo indica que a mulher com perda urinária esconde o seu problema devido à vergonha e a postura de alguns profissionais pode aumentar a inibição e impedir que ela expresse suas queixas durante a consulta. Porém, a falta de conhecimento dos profissionais sobre as implicações psicossociais da IU na vida da mulher podem levar a situações de indiferença e subestimação das queixas.

Diante disso os profissionais de saúde devem ser capazes de se mostrarem receptivos a este assunto tão delicado para a população acometida. Assim sendo, é de extrema importância incluir em todas as consultas de enfermagem questões para diagnosticar qualquer perda involuntária de urina, assim como, os serviços de saúde devem inserir em seu quadro de profissionais, enfermeiros especializados na assistência à população incontinente.

\section{REFERÊNCIAS}

1. Foldspang A, Mommsen S. The International Continence Society (ICS) incontinence definition: is the social and hygienic aspect appropriate for etiologic research? J Clin Epidemiol. 1997Sep; 50(9):1055-60.

2. Lopes MHBM, Higa R. Restrições causadas pela incontinência urinária à vida da mulher. Rev Esc Enferm USP. 2006 Mar; 40(1):34-41.

3. Higa R, Lopes MHBM. The impact of urinary incontinence on female nursing personnel. Rev Bras Enferm. 2007 Mar-Abr; 60(2):213-6.

4. Shaw C, Tansey R, Jackson C, Hyde C, Allan R. Barriers to help seeking in people with urinary symptoms. Fam Pract. 2001 Jan; 18(1):48-52.

5. Ashworth PD, Hagan MT. The meaning of incontinence: a qualitative study of non-geriatric urinary incontinence suffers. J Adv Nurs. 1993 Sep; 18(9):1415-23

6. Teunissen D, Van den Bosh W, Van Weel C, LagroJanssen T. It can always happen: the impact of urinary incontinence on elderly men and women. Scand J Prim Health Care. 2006 Sep; 24(3):166-73.

7. Higa R, Lopes MHBM, Turato ER. Psychocultural meanings of urinary incontinence in women: a review. Rev Latino-am Enfermagem. 2008 Ago; 16(4):779-86

8. Hägglund D, Ahlström G. The meaning of women's experience of living with long-term urinary incontinence is powerlessness. J Clin Nurs. 2007 Oct; 16(10):1946-54.

9. Borba AMC, Lelis MAS, Brêtas ACP. Significado de ter incontinência urinária e ser incontinente na visão das mulheres. Texto Contexto Enferm. 2008Jul-Set; 17(3):127-35.

10. Talbot LA. Coping with urinary incontinence. A conceptualization of the process. Ostomy Wound Manage. 1994 Mar;40(2):28-30.

11. Hägglund D, Wadensten B. Fear of humiliation inhibits women's care-seeking behavior for longterm urinary incontinence. Scand J Caring Sci. 2007 Sep; 21(3): 305-12.

12. Guarisi T, Pinto-Neto AM, Osis MJ, Pedro AO, Costa-Paiva LH, Faúndes A. Procura de serviço médico por mulheres com incontinência urinária. Rev Bras Ginecol Obst. 2001 Aug; 23(7):439-43.

13. Higa R, Lopes MHBM. Porque profissionais de enfermagem com incontinência urinária não buscam tratamento. Rev Bras Enferm. 2007 Set-Out; 60(5):503-6.

14. Silva L, Lopes MHBM. Incontinência urinária em mulheres: razão da não procura por tratamento. Rev Esc Enfermagem USP. 2009 Mar; 43(1):72-8.

15. Instituto Brasileiro de Geografia e Estatística. Ministério do Planejamento, Orçamento e Gestão. Estudo Especial sobre a Mulher - PNAD. [acesso 2009 Dez 21] Disponível em: http:/ / www.ibge.gov. br/home/presidencia/noticias/noticia_impressao. php?id_noticia $=1098$

16. Eksterman A. Abordagem psicodinâmica dos sintomas somáticos. Rev Bras Psicanál. 1994 Mar; 28(1):9-24.

17. Turato ER. Tratado da metodologia da pesquisa clínico-qualitativa: construção teórico-epistemológica, discussão comparada e aplicação às áreas da saúde e humanas. Petrópolis (RJ): Vozes; 2003.

18. Marshall G. "Snowballing technique". A dictionary of sociology. 1998. Encyclopedia.com. [acesso 2009 Dez 01] disponível em: http: / / www.encyclopedia. com/doc/1088-snowballingtechnique.html

19. Muchielli A. Les méthodes qualitatives. Coleção Que sais-je?. Paris (FR): Presses Universitaires de France; 1990.

20. Fontanella BJB, Campos CJG, Turato ER. Data collection in clinical-qualitative research: use of nondirected interviews with open-ended questions by health professionals. Rev Latino-am Enfermagem. 2006 Set; 14(5):812-20.

21. Minayo MCS. O desafio do conhecimento: pesquisa qualitativa em saúde. 8a ed. São Paulo: Hucitec; 2004. 
22. Bardin L. Análise de conteúdo. Lisboa (PT): Edições 70; 1977.

23. Goffman E. Estigma: notas sobre a manipulação da identidade deteriorada. Rio de Janeiro (RJ): LTCEditoras S.A.; 1998.

24. Horrocks S, Somerset M, Stoddart H, Peters TJ. What prevents older people from seeking treatment for urinary incontinence? A qualitative exploration of barriers to the use of community continence services. Family Practice. 2004 Nov; 21(6): 689-96.
25. Brittaina KR, Shaw C. The social consequences of living with and dealing with incontinence: A careers perspective. Social Science \& Medicine. 2007 Sep; 65(3):1274-83.

26. Fultz NH, Herzog AR. Self-reported social and emotional impact of urinary incontinence. J Am Geriatr Soc. 2001 Jul; 49(7):892-9.

27. Botanski L. As classes sociais e o corpo. Traduzido por Regina A. Machado. $3^{\text {a }}$ ed. São Paulo: Paz e terra; 2004.
Correspondência: Rosângela Higa

Rua Pedro Vieira da Silva, 595/DB62

13080-570 - Campinas, SP, Brasil

E-mail: rosangelahiga@bol.com.br
Recebido: 11 de março de 2010

Aprovação: 5 de outubro de 2010 